\title{
Impact of Weight Reduction Measures on Obesity Reduction - The Case of Canada
}

\begin{abstract}
By Stavroula Malla*, Solomon Akowuah ${ }^{ \pm} \&$ K. K. Klein
Obesity, and its related comorbidities, has become a pressing global health concern. This study follows an integrated approach of evaluating the health-related cost savings associated with the reduction of obesity incidence in Canada. A combination of metaanalysis and simulation using measured nationwide Body Mass Index data revealed that a reduction in calorie intake could lead to a 5\% to $10 \%$ weight loss, which could result in a nontrivial health-related average savings of CAD\$1.93 billion. This can be potentially achieved through the implementation and promotion of health-claims on lowcalorie diets. Stronger economic policies such as the introduction of subsidies on healthy foods and taxes on high calorie diets could potentially lead to socially optimal calorie consumption. A combination of initiatives and regulatory policy options are also discussed, which could stimulate prosperity by reducing the obesity epidemic.
\end{abstract}

Keywords: obesity, prevalence, meta-analysis, cost of illness approach, health-claims, regulatory policies

\section{Introduction}

Obesity is one of the biggest drivers of preventable chronic diseases and healthcare costs worldwide. More than 2.1 billion people, or almost $30 \%$ of the global population are overweight or obese ( $\mathrm{Ng}$ et al. 2014). The obesity issue is likely to worsen if the current trend continues - by 2030 it is estimated that almost half of the world's adult population will be overweight or obese (Kelly et al. 2008). In 2016, total health expenditure in Canada was about $\$ 228$ billion, or $\$ 6,299$ per person, representing $11 \%$ of Canada's GDP (CIHI 2017). It is no doubt that this crisis is not just a pressing health concern but also a threat to the global economy, and it requires immediate attention. This paper quantifies the potential benefits arising from the reduction of obesity incidents, potentially from weight reductions measures. The paper also attempts to analyse the potential benefits of obesity interventions measures like health claims on food products. The analysis provides context for a discussion of the potential regulatory policies and initiatives to address the obesity epidemic.

The increasing health care cost burden, morbidity rates, and mortality rates in Canada and other developed countries resulting from preventable diseases are a cause for great concern (CIHI 2013, WHO 2003). A significant number of these preventable health risk diseases are diet related. As a result of changing dietary and lifestyle patterns, certain diseases like obesity, hypertension, diabetes mellitus,

\footnotetext{
*Associate Professor, Department of Economics, University of Lethbridge, Canada. ${ }^{ \pm}$Professional Affiliate, Department of Economics, University of Lethbridge, Canada. *Professor, Department of Economics, University of Lethbridge, Canada.
} 
cardiovascular disease (CVD), and many others have become increasing causes of disability and premature deaths (WHO 2003).

Mounting evidence on awareness of the strong correlation between diet and health, coupled with increasing cost of health care in Canada have kindled interest in functional foods (Malla et al. 2013) ${ }^{1}$. Governments, policy makers, and interest groups are now focusing attention on the promotion of functional foods (Health Canada 2009). Health Canada has approved the use of 16 health claims on functional foods and food products since the year $2000^{2}$. For example, in 2014 Health Canada approved a health claim that consumption of ground whole flaxseed would lower blood cholesterol ${ }^{3}$. It has been shown that excess consumption or absence of certain vital nutrients in our daily diets is the main cause of most of the preventable diseases (Health Canada 2012). Obesity, which is a preventable health risk disease, has been shown to be a major public health issue in Canada (e.g., Godin et al. 2015, Katzmarzyk et al. 2001, Roberts et al. 2012). Increased calorie consumption is positively associated with obesity (e.g., Fontana et al. 2007, Redman et al. 2007). Cutler et al. (2003) suggested that increasing obesity incidence in the U.S. could be attributed to increased caloric intake.

Obesity has been shown to be a primary risk factor to quality of life in terms of morbidity and mortality (e.g., Edwards 2007, Katzmarzyk et al. 2001). Studies have also shown that obesity is the major risk factor for diseases such as heart disease and diseases of pulmonary circulation, cancer, cerebrovascular diseases (such as hypertension and stroke), and diabetes (e.g., Alter et al. 2012, Birmingham 1999, Tan 2011). Luo et al (2007) estimated the number of deaths due to obesity in Canada in 2004 to be $8,414^{4}$. Katzarzyk (2001) estimated that 13.5 percent of the deaths recorded in Canada in 2001 could have been avoided in the absence of obesity.

Birmingham (1999) estimated that the direct cost of obesity in Canada in 1997 to be $\$ 1.8$ billion, a figure representing 2.4 percent of the total health care expenditure in that year. In 2005, the total cost of obesity was $\$ 4.3$ billion (Public Health Agency of Canada 2009). In 2008, the cost of obesity was estimated to be $\$ 4.6$ billion (Public Health Agency of Canada 2011). This figure is regarded as a very conservative estimate since only eight of the diseases closely linked to obesity were taken into consideration. In 2006, a similar study that included the costs of 18 chronic diseases closely linked to obesity, found the total cost of obesity to be about $\$ 7.1$ billion (Public Health Agency of Canada 2011). The rate

\footnotetext{
${ }^{1}$ See Hobbs et al. (2014) for in-depth analysis and discussion of functional foods across a number of countries.

${ }^{2}$ The generally accepted definition of health claims in Canada is "any representation in labelling or advertising that states, suggests, or implies that a relationship exists between consumption of a food or an ingredient in the food and a person's health" (Health Canada 2012).

${ }^{3}$ For more details and complete list of approved health claims in Canada, see http://hc-sc.gc.ca/ fn-an/label-etiquet/claims-reclam/assess-evalu/index-eng.php.

${ }^{4}$ It is important to note that there is a significant difference between the methods used in both years so care must be taken when comparing the year 2000 figure to the 2004 figure. For example, while the 2004 study was based on all adult deaths, the 2000 study was based on deaths up to 65 years.
} 
of increase in health care expenditure in Canada was 7 percent per year from 2000 to 2010 (CIHI 2013). With continuous increases in health care costs, morbidity and mortality, it is important to put in place measures that minimize - if not eliminate - the incidence of obesity in Canada.

Several clinical studies have assessed the effects of calorie restriction on human body composition and weight using mainly controlled trials. ${ }^{5}$ Other studies have assessed the effects of measures like investments in research and development (R\&D), subsidies and taxes on obesity incidence (e.g., Alston et al. 2013, Cash et al. 2005, Leicester and Windmeijer 2004, Rickard et al. 2013, Mytton et al. 2007, Tiffin and Arnoult 2011). Although some studies have assessed the effects of health claims on other diseases like cholesterol levels and coronary heart disease (CHD) (e.g., Malla et al. 2016), a lot still remains to be done on the direct impacts of government-regulated health claims on obesity incidence in Canada.

It is important to empirically examine the effects of calorie restriction on obesity incidence using actual nationwide Body Mass Index (BMI) data, and further calculate the associated health-related cost savings. This study uses an integrated approach to examine the effect of calorie restriction on obesity/ overweight prevalence and the associated health care savings and related regulatory policies. In addition, this study analyses how implementation of government policies and regulations could help reduce obesity incidence, thereby resulting in a reduction of health care expenditures in Canada. Several other policy options and their implications are discussed.

The paper begins by describing the current situation with respect to regulatory policies and obesity, including discussion of functional foods, health claims, and consumers' responses. Estimates are made of the potential savings in healthrelated costs from potentially allowing health claims on low calorie diets and obesity. The analysis features a set of scenarios (base, low, and ideal) with different assumptions about weight loss, health impacts, and the relationship between obesity prevalence and health costs. These scenarios provide insights into the relative magnitude of potential health benefits, and explore the sensitivity of the results to key assumptions. A discussion of policy implications closes the paper.

This integrated approach allows us to systematically, consistently, and broadly analyse the issue of obesity and make policy recommendations that could significantly contribute to the reduction of the obesity epidemic. The study uses available Canadian data, but the findings are applicable to other constituencies as well. As former World Health Organization (WHO) Director-General Margaret Chan noted: "Not one single country has managed to turn around its obesity epidemic in all age groups" (WHO 2013). Obesity has become a big public health problem worldwide, a crisis that is not just a pressing health concern but a threat to the global economy as well. Hence, tackling obesity requires more sustainable

\footnotetext{
${ }^{5}$ For example, Civitarese et al. 2007, Colman et al. 2009, Fontana et al. 2004, Fontana et al. 2007, Guarente and Picard 2005, Heilbronn et al. 2006, Kok et al. 2005, Larson-Meyer et al. 2006, Racette et al. 2006, Redman et al. 2007, Redman et al. 2009, Villareal et al. 2006, Weiss et al. 2007.
} 
obesity related research and policy analysis as well as a coherent, sustained portfolio of initiatives, potentially implemented on a large scale.

\section{Regulatory Policies and Obesity}

\section{Functional Foods and Health Claims}

Health Canada acknowledges that diets can alter one's risk of developing or aggravating certain chronic health conditions (Health Canada 1998). The increasing economic burden of some diet related preventable diseases and the mounting evidence of the strong correlation between diet and health have attracted several policy responses from the government and other stakeholders (Health Canada 1998). Such responses have included mandatory nutrition labelling and the promotion of functional foods and health claims. Functional food consumption has the potential to improve well-being and reduce health care cost. There is no generally accepted definition for functional foods around the world. However, Health Canada (1998) defines functional food as "a food similar in appearance to, or may be a conventional food, is consumed as part of a usual diet, and is demonstrated to have physiological benefits and/or reduce the risk of chronic disease beyond basic nutritional functions" ${ }^{\prime}$.

Great efforts are being made to create awareness of the benefits of the nutrient content of foods such as the use of health claims. The main aim of these measures is to facilitate healthy eating choices that will, in the long run, translate into a healthier population and a reduction in steadily increasing health care costs (Malla et al. 2013).

A health claim on foods establishes a relationship between good health and the consumption of a food or food product. The generally accepted definition of a health claim in Canada is "any representation in labelling and advertising that states, suggests, or implies that a relation exist between the consumption of food or food constituent and health" (Health Canada 2012). According to Health Canada, health claims can take two main forms: generic claims and product specific claims ${ }^{7}$. Health Canada categorizes health claims into four main groups ${ }^{8}$ : therapeutic, disease risk reduction, functional claims, and general health claims ${ }^{9}$. The Food and Drug Act governs health claim usage on food and food products. Before a new health claim is approved and allowed to be used, a petitioner must apply to Health Canada and provide scientific evidence backing the claim. The evidence submitted by the petitioner is evaluated using three main criteria: causality, generalizability, and quality assurance (Health Canada 2009). The

\footnotetext{
${ }^{6}$ An example of a functional food is food high in fibre, which is noted for reducing one's risk of developing certain types of cancer.

${ }^{7}$ Generic claims can be used on any food item - if the item meets the criteria set out for the use of that claim - while product specific claims cannot be used for any food unless that specific food carrying the claim has undergone registration and enough supporting evidence has been provided.

${ }^{8}$ For more detailed discussion please see Hobbs et al. 2014.

${ }^{9}$ Functional claims were formerly known as structural/functional claims.
} 
causality criterion requires applicants to provide evidence establishing that the consumption of the food influences health outcomes. This is done mostly by providing human-based studies that establish a clear link between the consumption of the food and health. The generalizability criterion requires that the claim must be meaningfully generalizable to the broader population or a segment of the population. Lastly, the food on which the claim is used must conform to quality standards. If the claim is on a novel food, then a separate application for the novel food must be submitted either prior to, or with, the health claim application (Health Canada 2009) ${ }^{10}$. It is important to note that health claims that place the food under the definition of a drug needs pre-market approval and a regulation amendment (Health Canada 2009).

\section{Health Claims and Consumer Responses}

We begin by establishing a link between the use of health claims and the consumption of healthy diets. Specifically, we assert that the introduction of a health claim on low calorie diets and reduction in obesity will significantly encourage the consumption of low-calorie diets and discourage the consumption of high calorie diets. This assertion is based on the findings from numerous scientific/nutrition studies that suggest a strong correlation between the consumption of healthy (i.e., low calorie) foods and improved health; and, also, the findings from a comprehensive review of studies on health claims and consumer demand. In 2002, a joint WHO and FAO expert consultation on Diet, Nutrition and the Prevention of Chronic Diseases identified diet and lifestyle changes to be significantly related to the increasing epidemic of chronic diseases in the world (WHO 2003). Per the consultation, not only will changes in one's diet affect a person's present health conditions, it will also affect that person's future chances of developing any of the chronic diseases (like cancer, diabetes, etc.).

Health claim usage has been shown to significantly improve the understanding of the relationship that exists between diet and health (e.g., Barreiro-Hurlé et al. 2010, Williams 2005). Several studies found that consumers value health claims and health information that link the consumption of healthier foods or food constituents to reduced risk of certain diseases (e.g., Brown and Schrader 1990, Levy and Stokes 1987, Moon et al. 2011, Williams 2005). In addition, evidence suggests that consumers are willing to pay price premiums for the benefits they derive from healthy or health-enhancing food products (e.g., Barreiro-Hurlé et al. 2008, Larue et al. 2004, Marette et al. 2010, Maynard and Franklin 2003, Milligan et al. 2010, Teratanavat and Hooker 2006, West et al. 2002). The paragraph below provides evidence of instances where the introduction/promotion of health information/health claims resulted in an increase (decrease) of healthy (unhealthy) food products.

Ippolito and Mathios (1991) examined the market of ready-to-eat cereals for the periods preceding and after a ban on health claims usage on cereal products in

\footnotetext{
${ }^{10}$ According to Health Canada novel foods are foods that have been produced through new processes, that do not have a history of safe use as a food, or that have been modified by genetic manipulation (Health Canada 2020).
} 
the US. The authors found that in addition to the improvement of consumer awareness of the link between fibre consumption and development of cancer, there was a significant increase in fibre cereal consumption after the ban on the health claim was lifted. There was a significant shift of market share towards high-fibre cereals when health claim usage was allowed ${ }^{11}$. Lalor et al. (2011) examined how health claims on foods influence peoples' reactions towards those foods. It was observed that health claims had a significant impact on the purchasing power of the elderly, women with young children, and people with close friends/relatives suffering from certain diseases. Aschemann-Witzel and Hamm (2010) found that consumers preferred food products with health claims and nutritional information to those without. Consumers who purchased food products with health claims perceived the food to be much healthier than similar foods without health claims. Levy and Stokes (1987) empirically examined the influence of a claim linking the consumptions of foods rich in fibre and the prevention of certain types of cancer. Findings from the study suggested that Kellogg Company's campaign to promote the health claims led to a significant shift in market share from non-high fibre cereals to high-fibre cereals ${ }^{12}$. Brown and Schrader (1990) used a cholesterol information index to assess the impact of cholesterol information on the demand for shell eggs in the $\mathrm{US}^{13}$. Cholesterol information led to a decrease in per capita shell egg consumption from $16 \%$ to $25 \%$. A positive interaction was observed between egg price and cholesterol, which suggested a reduction in absolute price elasticity of shell eggs resulting from availability of cholesterol information. Kozup et al. (2003) argued that health claims can have a significant impact on product attitudes and purchase intentions even in the absence of nutritional information and suggested that if health claims can be justified, their usage could be very beneficial to restaurants.

Although the studies discussed above provide evidence of a significant link between health claim usage and foods that carry the claim, it must be noted that having the health claims alone might not necessarily yield the required results. It is necessary that the claims have the endorsement of a trusted authority like the government (Wansink and Cheney 2005). Furthermore, the success of the health claim also depends on specific efforts aimed at promoting the awareness of the claim - the link between good health and consumption of the foods that carry the claims (Aschemann-Witzel and Hamm 2010).

Considering obesity, mounting evidence suggests that there is a strong link between calorie restriction and weight loss (e.g., Fontana et al. 2007, Redman et al.

\footnotetext{
${ }^{11}$ Weighted fibre content increased by $7 \%$ after the health claim was allowed (i.e., an increase from 1.64 grams per ounce in 1978-1984 to 1.75 grams per ounce in 1985-1987).

${ }^{12}$ There was a progressive increase in the market share of high-fibre cereals during the entire 48 weeks of assessment. Twenty-four weeks into the campaign, there was also a sharp increase in the market share of Kellogg company's All-Bran product (which is very rich in fibre). An increase of market share from $0.99 \%$ to $1.46 \%$ was recorded (i.e., representing a relative increase of $47 \%$ ). The sales of other high-fibre products of Kellogg Company rose by $0.3 \%$, which represented a relative increase of about $14 \%$.

${ }^{13}$ The study defined cholesterol information as the relationship between the presence of cholesterol in diet and the development of arterial diseases-diseases associated with high blood cholesterol.
} 
2007, Redman et al. 2009, Weiss et al. 2007). Figure 1 graphically depicts the impact of health claims on the consumption of unhealthy diets - in this case the consumption of high calorie diets. The publicly funded nature of the health care system in Canada and many other countries leads to a moral hazard problem whereby individuals might not make private diet choices that are socially optimal as the consequences of such poor diet choices are borne by others. This implies that people might tend to under-consume healthy foods and over-consume unhealthy foods. A negative externality is created when an individual or group of people making poor diet choices fails to fully pay for the cost of their actions (Alston et al. 2012, Elston et al. 2010, Strand 2005). According to Elston et al. (2010), a significant portion of the expenditure on publicly funded health insurance programs goes towards obesity related costs.

Figure 1. Impact of Health Claims on the Intake of High Calorie Diets

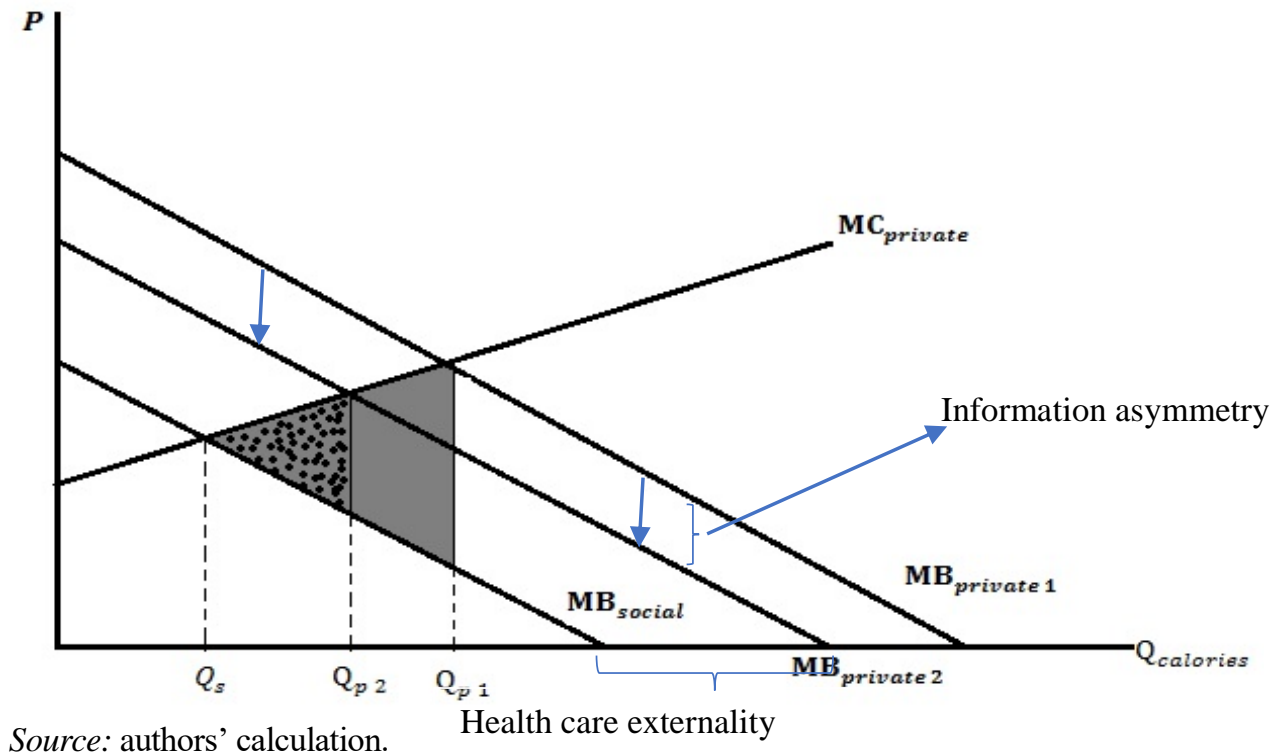

The health benefits from functional foods cannot be easily evaluated by consumers without labelling. In the absence of health information on food products that inform consumers of the benefits or dangers of the nutritional contents of foods, individuals have less incentive to make socially optimal diet decisions. Consumers might not even know the health benefits/costs of the food. Individuals might consider only the immediate satisfaction $\left(\mathrm{MB}_{\text {private } 1}\right)$ derived from making such diet choices (consumption of high calorie diets) without having full information of the benefits/costs associated with the food. Studies suggest that some consumers might not act rationally in their diet choices since they place more importance on the satisfaction they get from excess calorie consumption and neglect the long-term implications on their health (Ananthapavan et al. 2014, Alston et al. 2012, Efrat and Efrat 2012, Swinburn, et al. 2011, Cawley 2010, Moodie et al. 2006). Loewenstein et al. (2007) and Alston et al. (2012) suggest that individuals place higher weights on present benefits; therefore, they easily rationalise that the immediate satisfaction from their diet choices exceeds the long- 
term cost of such choices. According to Efrat and Efrat (2012), not all individuals can be considered as free agents when it comes to matters concerning their diet choices (e.g., children are not able to make rational diet decisions). Likewise, because of physiological, self-control, and cognitive challenges, some adults also are not able to make healthy diet choices.

It is sometimes argued that there is abundant health information on the risk of excessive calorie intake and obesity. However, comparing the level of health information provided by food manufacturers and suppliers to that provided by the government shows a significant difference. Information from the government is significantly less (Efrat and Efrat 2012). Since food manufacturers and suppliers are driven by the profitability of their activities, the information they provide may not necessarily be in the best interest of the consumer (Cawley 2004). Furthermore, evidence suggests that mere access to this information does not necessarily guarantee that consumers will be able to fully understand or interpret the information to serve as guidance for their diet decisions (Rothman et al. 2006).

Considering the market failures that result from health care externalities, irrational consumer behaviour, and information asymmetry, it is important that some form of government intervention be introduced. If the government approves and promotes the use of a health claim on low calorie diets and obesity, it is expected that some consumers will revise their preference for high calorie diets and switch to a lower calorie one. Although consumers might not pay directly the full cost of poor diet choices, their utility for high calorie diets could be reduced when they become more aware of the health risks and costs of high-calorie diets and the benefits of low-calorie diets. In addition, the approval of a health claim by a credible source like the government will boost consumer confidence in the message that the health claim carries. Thus, the marginal private benefit curve will shift from $\mathrm{MB}_{\text {private } 1}$ to $\mathrm{MB}_{\text {private } 2}$ corresponding to a reduction in caloric intake from $Q_{p 1}$ to $Q_{p 2}$ (in Figure 1). This will also lead to a reduction in the loss to society (DWL) from the gray shaded area to the dotted area. Although the health claim could reduce the private optimal quantity closer to the socially optimal, further stricter policies would be needed to reach the socially optimal level $\left(Q_{S}\right)$. This is because even in the presence of health information, consumers might still not consume at the optimal level because of the existence of health care externalities.

Therefore the literature suggests that health claims for low calorie diets should lead to a reduction in calorie intake, consistent with the expectation that credible health claims reduce the consumers' information problem. In this context, if it helps bolster consumer confidence, the regulatory landscape governing health claims might facilitate the establishment of credible health claims by the private sector. We now turn to an evaluation of the prevalence and determinants of obesity and of the economic benefits of the low calorie diets health claims. 


\section{Methods of Analysis}

Cost of Illness approach is used to estimate the potential economic benefits of improved health resulting from obesity intervention policy in Canada ${ }^{14}$. The COI approach generates relatively conservative estimates and has some precedence in the literature. The COI approach is considered an effective analytical tool to estimate health-related cost savings (e.g., Gray et al. 1998, Gyles et al. 2010, Malla et al. 2007, Malla et al. 2016).

The analysis is summarized in three steps. First, if the approval of health claims for low calorie diets encourages reduction in caloric intake, the potential weight loss in the population is estimated. These estimates are based on an extensive review of the scientific literature measuring the effects of calorie restriction on individuals' weight and insights from a review of consumer literature. Second, the reduction in obesity prevalence due to restriction of calories in the daily diets of individuals is estimated, based on simulations of the dataset. Finally, the reductions in health-related costs from the reduced prevalence of obesity are estimated. These estimates are based on available data and peerreviewed scientific literature. A "Base" scenario set of estimates is provided, along with a sensitivity analysis around the core assumptions to give "Low" and "Ideal" scenarios.

\section{Step 1: Calorie Restriction and Weight Loss}

Step one estimates the potential weight loss that will result from reduced caloric intake. We conducted a meta-analysis of medical/nutrition literature that was based on dietary intervention studies (human controlled clinical trials). Clinical trials on the influence of calorie restriction (CR) on human body composition have suggested that the reduction of caloric intake has a non-trivial influence on the weight of people who practice it (e.g., Fontana et al. 2007, Redman et al. 2007, Redman et al. 2009, Tsai and Wadden 2006, Villareal et al. 2006, Weiss et al. 2007). The restriction of calories in one's diet takes two main forms: low-calorie diets (LCD) and very low-calorie diets (VLCD). LCD is the restriction of caloric intake to about $800-1500 \mathrm{kcal} /$ day while VLCD is the restriction of caloric intake to about $250-800 \mathrm{kcal} /$ day (Initiative 1998). Findings from studies suggest that the effects of both interventions on weight loss after a year are not significantly different from each other (Wadden et al. 1994).

To estimate the weight loss resulting from restricting one's caloric intake, a meta-analysis of several human clinical studies assessing the impact of CR on weight was conducted. A computer search of Medline (via OVID) was conducted with the key words "calorie restriction" and "weight loss" or "weight reduction".

\footnotetext{
${ }^{14}$ Other methods to estimate the cost of illness that have been used by other researchers include Willingness to Pay (WTP), the Disability-Adjusted Life Years approach (DALY), QualityAdjusted Life Years (QALYs), Cost Benefit Analysis, Healthy Years of Life Gained (HYLG), and Cost-Utility (cost effectiveness). While acknowledging that other methods could be used to estimate health-related cost savings, considering the nature of analysis to be conducted and the data available, the most suitable method is a variation of the COI approach.
} 
Moreover, an extensive search of the references of relevant studies was performed. The main criterion used for accepting and including studies into the meta-analysis was that the weight intervention should include at least one form of calorie restriction in diets. This reduces the possibility of including studies where weight loss was achieved accidentally, or CR was not the intended intervention. Table A.1 in Appendix 1 gives a detailed presentation of the findings from the meta-analysis. The available results suggest that, on average, CR will result in 10.61 percent \pm 1.42 percent loss in weight within a period of one year.

Based on peer-reviewed evidence of strong correlation between health claims/health information promotion and consumer demand for healthy food products, it can be inferred that if the necessary attention is given to the health claim on low calorie diets and obesity, the intake of calories could be significantly reduced. The analysis is based on clinical trials' recommended levels for calorie restriction and the associated weight loss estimates, as well as a review of consumers' economics literature.

\section{Step 2: Reduction in Obesity Prevalence Resulting from Weight Loss}

Step two involves estimating the reduction in obesity prevalence from the restriction of calories in the daily diets of individuals. A weight reduction simulation was performed on the dataset to observe the effect of the estimated weight loss in step one on obesity prevalence in Canada. In other words, the study ran a simulation of the dataset to observe the changes to obesity prevalence in Canada if overweight or obese people were to reduce their weight by 10.61 percent \pm 1.42 percent. To simplify the analysis, the estimated weight loss was rounded to 10 percent. To evaluate the corresponding reduction in obesity prevalence resulting from reduced intake of high calorie diets, the weight loss estimate in step one was deducted from the actual weights of Canadians who are either overweight or obese. The BMI of everyone in the dataset was then recalculated to evaluate the "new" prevalence of obesity in Canada resulting from the estimated weight reduction. The new obesity prevalence estimate was then compared to the obesity prevalence prior to the imposition of the weight reduction restriction to evaluate the reduction in obesity prevalence associated with the reduction of caloric intake. To ensure robustness of the estimate, the analysis was repeated by considering another scenario. A modest weight loss of 5 percent was used to re-run the simulation. According to the U.S Food and Drug Administration (FDA), a weight loss of even 5 percent is considered as clinically significant (Moyer 2012).

\section{Step 3: Health-related Cost Savings Resulting from Reduction in Obesity Prevalence}

The final step in the analysis is to estimate the potential health-related cost savings to Canada resulting from calorie restriction. In 2006, obesity was estimated to cost Canada a total of $\$ 7.1$ billion (Public Health Agency of Canada 2011). Out of this amount, $\$ 3.2$ billion was in direct cost, while the remaining $\$ 3.9$ 
billion was indirect ${ }^{15}$. In order to estimate the potential health-related cost savings, the 2006 obesity cost estimate was adjusted to reflect current monetary values. The consumer price index for health and personal care data from Statistics Canada was used to adjust the 2006 estimate of $\$ 7.1$ billion to a 2018 level of $\$ 8.44$ billion (Statistics Canada 2019). A similar adjustment of disease cost was done by Gyles et al. (2010) and Malla et al. (2016).

To estimate the potential health-related cost savings, we established the relationship between reduction in obesity prevalence and reduction in health care expenditure on the disease. Although a reduction in prevalence will result in a reduction in cost, the magnitude of the change in health care expenditure that would result from reduction in overweight/obesity prevalence is unclear. We consider different scenarios to estimate the potential health-related savings. The first scenario, "Ideal", assumes an optimistic relationship between reduction in prevalence and health-related cost savings. It is assumed that there is a linear 1:1 relationship between reduction in the incidence of a disease and health-related cost savings (i.e., a 1 percent reduction in the prevalence of obesity will result in a 1 percent reduction in cost). This is consistent with the approach used in Gray et al. (1998), Malla et al. (2007) and Malla et al. (2016).

A second scenario, "Base", was considered where the various cost components of the disease (direct cost: hospital care, physician, drugs, all other health costs; and indirect costs) were taken into consideration in establishing the relationship between changes in prevalence and changes in health cost savings (a similar approach was used by Gyles et al. 2010) ${ }^{16}$. Table A.2 in Appendix 2 provides a summary of the percentage reduction in the various components of health care cost resulting from a 1 percent reduction in obesity prevalence. To make the analysis comparable to the "Ideal" case scenario, a weighted average of the percentage reductions in the various components of obesity cost resulting from a 1 percent reduction in the prevalence of obesity is evaluated ${ }^{17}$. This gives a 1:0.83 relationship between reduction in disease prevalence and reduction in health care expenditure. That is, a 1 percent reduction in the prevalence of obesity will result in a 0.83 percent reduction in health care expenditure on the disease. In evaluating the weighted average, we used the total cost of each obesity cost component as its respective weight. The evaluated weighted average was then used to estimate the total health-related cost savings corresponding to the total percentage reduction in obesity prevalence.

Finally, a third scenario, "Low", which considers a more conservative relationship between reduction in disease prevalence and health-related cost savings was examined. The "Low" scenario assumes that there is a 1:0.5 relationship between reduction in the incidence of a disease and health-related cost savings (i.e., a 1 percent reduction in the prevalence of obesity would result in a 0.5

\footnotetext{
${ }^{15}$ Direct cost includes hospital care expenditure, physician services, drug cost, health research cost, cost of services of other health professionals, and other health care cost. The indirect cost is mainly the cost incurred due to productivity loss resulting from mortality and morbidity (Public Health Agency of Canada 2014).

${ }^{16}$ For more details on "Base" scenario calculations, see Appendix 3.

${ }^{17}$ The expenditure incurred on each component of the total health cost is used as its weight.
} 
percent reduction in health-related cost). In summary, the scenarios are based on a wide-ranging set of assumptions and the results will necessarily be sensitive to these assumptions. Where possible the assumptions are based on insights from peer-reviewed scientific literature. To ensure the estimates are as robust as possible, and consistent with previous studies using the COI method (e.g., Gray et al. 1998, Gyles et al. 2010, Malla et al. 2007, Malla et al. 2016), different scenarios provide a range of outcomes.

\section{Data}

Different sources of data were used for different aspects of the analyses. For the estimation of obesity prevalence, confidential micro-level data from the 2015 Canadian Community Health survey (CCHS) provided by Statistics Canada were used. Furthermore, a combination of data from the 2015 CCHS and data obtained through reviews of medical and nutritional literature based on human clinical trials was used to perform the weight reduction simulation. The 2015 CCHS data were based on measured heights and weights. It has been shown that data based on selfreported heights and weights tends to underestimate the prevalence of obesity (Bélanger-Ducharme and Tremblay 2005, Goldman et al. 2011, Le Petit and Berthelot 2005, Tjepkema 2006, Torrance et al. 2002). ${ }^{18}$ A possible explanation of this problem is that people are more inclined to increase their height estimates and reduce their weights when self-reporting (Tjepkema 2006). Hence, it is essential to use data based on measured heights and weights.

Even though more recent versions of the CCHS are available, this study uses only the 2015 CCHS. The decision was made based on two main reasons - the annual versions provide data on mostly self-reported heights and weights of Canadians and the focus of the data is not on nutrition. The 2015 CCHS dataset compiled information from all 10 provinces in Canada focusing on people aged 1 and over. A total of 20,487 people were sampled. The sampling strategy used ensured that the data fairly represented the Canadian population. Among the groups of people excluded from the study are people under the age of 18 years, full-time members of the Canadian Forces, people living in the Territories, First Nation Reserves or Crown Lands, in prisons or care facilities and some remote areas. The final sample sized after eliminating individuals with only self-reported heights and weights, non-responses and missing information was 9,300. The study made use of the sampling weight provided by the 2015 CCHS.

\footnotetext{
${ }^{18}$ The comparison of the 1978-1979 Canada Health Survey (measured data) to the 1981 Canada Fitness Survey (self-reported data) by Torrance et al. (2002) indicated that, while the latter reported the percentage obese to be 9 percent, the former reported the percentage of people obese to be 13 percent. Moreover, comparing the 1988 Campbell Survey on Well-Being (self-reported data) with the 1986-1992 Heart Health Survey (measured data) also revealed that the percentage of people obese was 10 percent and 14 percent respectively. In addition, the estimated percentage of Canadians obese in 2003 (estimate based on self-reported heights and weights) was 15.2 percent, which is significantly below the 2004 estimate of 23.1 percent, which was based on measured heights and weights (Tjepkema 2006).
} 


\section{Results}

Two main results from the COI analysis are presented in this section. The first part of this section presents findings from the weight loss simulations resulting from possible implementation and promotion of the health claim on "low calorie diets and obesity". The second part presents the results of the potential healthrelated cost savings estimations corresponding to the evaluated reductions in obesity prevalence. Various cases were considered in evaluating the potential reduction in obesity prevalence resulting from a weight loss simulation of the 2015 CCHS dataset. The cases considered include 10 percent and 5 percent weight loss simulations performed on 100 percent, 60 percent, and 30 percent of overweight and obese individuals in the $2015 \mathrm{CCHS}$ to estimate the potential reductions in obesity prevalence in Canada. Table 1 gives the details of 10 percent and 5 percent weight loss simulations on all persons overweight or obese. The process was repeated by performing the simulation on 60 percent and 30 percent randomly selected individuals who are overweight or obese, respectively. The simulation on the randomly selected people was repeated several times to estimate the final overall impact of the $5 \%$ and $10 \%$ weight loss.

Table 1. Simulation Results after Weight Loss Estimate is Applied to Overweight and Obese Individuals

\begin{tabular}{|c|c|c|c|c|c|c|}
\hline \multicolumn{7}{|c|}{$\begin{array}{l}\text { Prevalence of overweight and obesity after weight loss is applied to all persons overweight } \\
\text { or obese }\end{array}$} \\
\hline \multirow[t]{2}{*}{$\begin{array}{l}\text { Percentage } \\
\text { Weight Loss }\end{array}$} & \multicolumn{2}{|c|}{$\begin{array}{l}\text { Prevalence before } \\
\text { weight loss }\end{array}$} & \multicolumn{2}{|c|}{$\begin{array}{l}\text { Prevalence after weight } \\
\text { loss }\end{array}$} & \multicolumn{2}{|c|}{$\begin{array}{l}\text { Percentage change in } \\
\text { prevalence }\end{array}$} \\
\hline & $\begin{array}{l}\text { Overweight } \\
\%\end{array}$ & $\begin{array}{c}\text { Obesity } \\
\%\end{array}$ & $\begin{array}{l}\text { Overweight } \\
\%\end{array}$ & $\begin{array}{c}\text { Obesity } \\
\%\end{array}$ & $\begin{array}{l}\text { Overweight } \\
\%\end{array}$ & $\begin{array}{c}\text { Obesity } \\
\%\end{array}$ \\
\hline $5 \%$ & 35.24 & 26.97 & 32.14 & 20.01 & -9 & -26 \\
\hline $10 \%$ & 35.24 & 26.97 & 26.55 & 14.55 & -25 & -46 \\
\hline \multicolumn{7}{|c|}{$\begin{array}{l}\text { Prevalence of overweight and obesity after weight loss is applied to } 60 \% \text { randomly selected } \\
\text { individuals who are overweight or obese }\end{array}$} \\
\hline $5 \%$ & 35.24 & 26.97 & 33.29 & 22.84 & -6 & -15 \\
\hline $10 \%$ & 35.24 & 26.97 & 29.64 & 19.53 & -16 & -28 \\
\hline \multicolumn{7}{|c|}{$\begin{array}{l}\text { Prevalence of overweight and obesity after weight loss is applied to } 30 \% \text { randomly selected } \\
\text { individuals who are overweight or obese }\end{array}$} \\
\hline $5 \%$ & 35.24 & 26.97 & 34.34 & 24.87 & -0.3 & -8 \\
\hline $10 \%$ & 35.24 & 26.97 & 32.51 & 23.21 & -8 & -14 \\
\hline
\end{tabular}

Source: authors' calculation.

Table 1 shows that by imposing a 10 percent weight loss restriction on all persons overweight or obese, overweight and obesity prevalence reduces from 35.24 percent to 26.55 percent and 26.97 percent to 14.55 percent, respectively. This results in a reduction of the overweight and obesity prevalence by 25 percent and 46 percent, respectively. Similarly, after imposing a 5 percent weight loss restriction on the data, overweight and obesity prevalence reduces from 35.24 percent to 32.14 percent and 26.97 percent to 20.01 percent, respectively. That is, 
overweight and obesity prevalence reduces by 9 percent and 26 percent, respectively.

To test the sensitivity of these results, we relaxed the assumption that the health claims will be successful in persuading all overweight and obese persons to reduce their weight (i.e., 100 percent success rate). Assuming a 60 percent success rate of the health claim, we repeatedly and randomly selected 60 percent of the overweight and obese people to apply 5 and 10 percent weight loss restrictions on them. Overweight and obesity prevalence were reduced by 16 percent and 28 percent, respectively, after a weight loss restriction of 10 percent was imposed. Similarly, a 5 percent weight loss restriction resulted in overweight and obesity prevalence reduction of 6 and 15 percent, respectively.

Finally, the process was repeated by considering a more conservative success rate of a health claim. After a weight loss of 10 (5) percent was randomly and repeatedly applied to 30 percent of the overweight and obese people, overweight and obesity prevalence were reduced by 8 percent and 14 percent, respectively ( 3 percent and 8 percent, respectively).

\section{Potential Health-Related Cost Savings Resulting from the Reduction in Obesity} Prevalence

The results from all three scenarios of the simulations are presented in Table 2 (i.e., the situation where the weight loss simulations are performed on all, 30\%, and $60 \%$ of people overweight or obese). When a 10 percent weight loss simulation was performed on all overweight or obese persons, the potential healthrelated cost savings for the ideal, base, and low scenarios are $\$ 3.89$ billion, $\$ 3.23$ billion, and $\$ 1.94$ billion, respectively. Similarly, when a 5 percent weight loss simulation was performed on all overweight and obese persons, the potential health-related cost savings for the ideal, base, and low scenarios are $\$ 2.18$ billion, $\$ 1.81$ billion, and $\$ 1.09$ billion, respectively. Moreover, when a 10 percent weight loss simulation was performed on 60 percent randomly and repeatedly selected overweight or obese individuals from the dataset, the potential health-related cost savings for the ideal, base, and low scenarios are $\$ 2.33$ billion, $\$ 1.93$ billion, and $\$ 1.16$ billion, respectively. Likewise, when a 5 percent weight loss simulation was performed on 60 percent of individuals, the potential health-related cost savings are $\$ 1.29$ billion, $\$ 1.07$ billion, and $\$ 650$ million for the ideal, base, and low scenarios, respectively. Finally, when a 10 (5) percent weight loss simulation was performed on 30 percent randomly and repeatedly selected overweight/obese individuals, obesity health-related cost reduces by $\$ 1.18$ billion, $\$ 980$ million, and $\$ 590$ million (\$660, $\$ 550$, and $\$ 330$ million), respectively.

The results are summarized in three main scenarios and presented in Table 3. Obesity health related cost of $\$ 3.89$ billion could be saved if "all" individuals overweight/obese lose 10 percent of their weight, based on an optimistic assumption that a 1 percent weight loss would result in a 1 percent reduction in obesity health related cost. Similarly, for the base/expected scenario, $\$ 1.93$ billion in health-related cost could be saved, if "60\%" of individuals (overweight/obese) lose 10 percent of their weight, based on 1:0.83 ratio between prevalence change 
and cost. Lastly, regarding the pessimistic or very conservative scenario, health related cost savings could be $\$ 330$ million if "30\%" of overweight/obese individuals lose $5 \%$ of their weight, given a prevalence change to cost ratio of 1:05. In summary, health related cost savings due to the reduction of obesity/ overweight prevalence, potentially due to implementation/promotion of healthinformation/health-claims on "low calorie diets and obesity", could be very significant and could be projected to amount to $\$ 1.93$ billion (base case/expected).

Table 2. Health-Related Cost Savings Estimation

\begin{tabular}{|c|c|c|c|c|c|c|c|c|}
\hline \multicolumn{9}{|c|}{ Reduction in health-related cost after weight loss is applied to all persons obese/overweight } \\
\hline \multirow[t]{2}{*}{ Scenario } & \multicolumn{2}{|c|}{$\begin{array}{l}\text { Percentage reduction } \\
\text { in obesity prevalence } \\
\text { as a result of: }\end{array}$} & \multirow{2}{*}{$\begin{array}{l}\text { Total health } \\
\text { care cost of } \\
\text { obesity in } \\
\text { Canada } \\
\text { (billion CAD } \\
\$ \text { ) }\end{array}$} & \multirow{2}{*}{$\begin{array}{l}\text { Relationship } \\
\text { between } \\
\text { change in } \\
\text { prevalence } \\
\text { and cost }\end{array}$} & \multicolumn{2}{|c|}{$\begin{array}{l}\text { Percentage } \\
\text { reduction in } \\
\text { health care cost } \\
\text { as a result of: }\end{array}$} & \multicolumn{2}{|c|}{$\begin{array}{l}\text { Total reduction in } \\
\text { health expenditure } \\
\text { on obesity as a result } \\
\text { of: (billion CAD \$) }\end{array}$} \\
\hline & $\begin{array}{c}5 \% \\
\text { weight } \\
\text { loss }\end{array}$ & $\begin{array}{l}10 \% \\
\text { weight } \\
\text { loss }\end{array}$ & & & $\begin{array}{c}5 \% \\
\text { weight } \\
\text { loss }\end{array}$ & $\begin{array}{c}10 \% \\
\text { weight } \\
\text { loss }\end{array}$ & $\begin{array}{c}5 \% \\
\text { weight } \\
\text { loss }\end{array}$ & $\begin{array}{l}10 \% \\
\text { weight } \\
\text { loss }\end{array}$ \\
\hline Low & 26 & 46 & 8.44 & 1:0.5 & 13 & 23 & 1.09 & 1.94 \\
\hline Base & 26 & 46 & 8.44 & 1:0.8 & 21 & 38 & 1.81 & 3.23 \\
\hline Ideal & 26 & 46 & 8.44 & $1: 1$ & 26 & 46 & 2.18 & 3.89 \\
\hline
\end{tabular}

Reduction in health-related cost after weight loss is applied to $60 \%$ randomly selected individual who are obese/overweight

\begin{tabular}{|l|c|c|c|c|c|c|c|c|}
\hline Low & 15 & 28 & 8.44 & $1: 0.5$ & 8 & 14 & 0.65 & 1.16 \\
\hline Base & 15 & 28 & 8.44 & $1: 0.8$ & 13 & 23 & 1.07 & $\mathbf{1 . 9 3}$ \\
\hline Ideal & 15 & 28 & 8.44 & $1: 1$ & 15 & 28 & 1.29 & 2.33 \\
\hline
\end{tabular}

Reduction in health-related cost after weight loss is applied to $30 \%$ randomly selected individual who are obese/overweight

\begin{tabular}{|l|c|c|c|c|c|c|c|c|}
\hline Low & 8 & 14 & 8.44 & $1: 0.5$ & 4 & 7 & $\mathbf{0 . 3 3}$ & 0.59 \\
\hline Base & 8 & 14 & 8.44 & $1: 0.8$ & 6 & 12 & 0.55 & 0.98 \\
\hline Ideal & 8 & 14 & 8.44 & $1: 1$ & 8 & 14 & 0.66 & 1.18 \\
\hline
\end{tabular}

Source: authors' calculation.

Table 3. Summary of Cases/Scenarios of Health-Related Cost Savings

\begin{tabular}{|l|c|c|}
\hline Groups & Cases/Scenarios & Health care savings \\
\hline Optimistic & $\begin{array}{c}\text { All individuals overweight/obese }+10 \% \text { weight } \\
\text { loss simulation }+1: 1\end{array}$ & \$3.89 billion \\
\hline Expected & $\begin{array}{c}60 \% \text { randomly and repeatedly selected } \\
\text { overweight/obese individuals }+10 \% \text { weight loss } \\
\text { simulation }+1: 0.83\end{array}$ & \$1.93 billion \\
\hline Pessimistic & $\begin{array}{c}30 \% \text { randomly and repeatedly selected } \\
\text { overweight/obese individuals }+5 \% \text { weight loss } \\
\text { simulation }+1: 0.05\end{array}$ & \$330 million \\
\hline
\end{tabular}

Source: authors' calculation. 


\section{Policy Implication}

Findings from this study confirmed that implementation and promotion of a health claim on low calorie diets and obesity as an intervention policy to tackle the obesity menace could have significant implications on consumption of calories, obesity incidence, and health care expenditures in Canada. Our findings suggest that obesity incidence could be reduced by 8 to 46 percent if the health claim were implemented and promoted. Accordingly, health care expenditures could be reduced by a base amount of $\$ 1.93$ billion, ranging between $\$ 330$ million and $\$ 3.89$ billion. Therefore, attention should be given to the health claim and, if possible, implemented and promoted.

Three main types of market failures could be associated with the problem of obesity: information asymmetry, irrational consumer behaviour, and health care externalities. While education of the general populace and the introduction and promotion of health claims on low calorie diets and obesity could address the problem of information asymmetry and irrational consumer behaviour, policies such as subsidies and taxes could address the problem of the health care externalities. The existence of these three types of market failures provides an economic justification for the government to introduce stronger policies like taxes on high calorie foods and subsidies on low calorie foods. Information on both the health benefits and the potential public health-related cost savings could provide further bases for such intervention. Freebairn (2010) argued for government intervention by citing two main sources of obesity spillover effects-the use of revenue generated from general taxes to finance health care costs and the insufficient contributions by obese individuals in the form of income taxes to government revenue (i.e., obese people take too many sick days so they are less productive).

These policies could significantly reduce the incidence of obesity since it could discourage excess consumption of high-calorie foods and encourage the consumption of low-calorie ones. Studies suggest that price reduction of healthy foods significantly encourages the consumption of such foods (e.g., Epstein et al. 2006, French 2003). Goldman et al. (2011) found that increasing the prices of high calorie foods resulted in the reduction of obesity in the long run in the U.S. Such intervention policies are important because some individuals will make diet choices that are privately but not socially optimal. Even in the presence of perfect information and health claims, consumers will consume more foods with high calories than the socially optimal amount due to health care externality. Consumers over-consume unhealthy products if they do not bear the full cost of their poor diet choices. This results from the nature of the publicly funded health care system in Canada. Hence, the privately optimal level might be significantly higher than the socially optimal level, as depicted in Figure 2.

The introduction of specific policies like subsidies on low calorie diets could further discourage the intake of high calorie diets and could result in a socially optimal outcome. Figure 2 shows how a subsidy on low calorie diets could result 
in further reduction of caloric intake following a reduction due to a health claim ${ }^{19}$. With the appropriate amount of subsidy, the marginal private benefit curve will shift from $\mathrm{MB}_{\text {private } 2}$ to $\mathrm{MB}_{\text {social }}$ (where the marginal private benefit curve coincides with the marginal social benefit curve), corresponding to a reduction in caloric intake from $\mathrm{Q}_{p 2}$ to $\mathrm{Q}_{s}$. At $\mathrm{Q}_{s}$, people will consume at the socially optimal level where there is no loss to the society. It is, however, important to note that not all subsidies will result in the above outcome. For instance, it is argued that the introduction of subsidies on certain food products like corn and other cereal products in the U.S. contributed to the problem of obesity (Pollan 2007, Ludwig and Pollack 2009). Such subsidies are believed to make high calorie foods cheaper and more abundant. On the other hand, findings from studies (e.g., Chang and Lauderdale 2005), including this present study, suggest that obesity is correlated with income. As such, "thin subsidies" might be regressive and in the long run contribute to the obesity epidemic (Muller et al 2017).

Figure 2. Impact of Subsidies and Fat Taxes on Caloric Intake

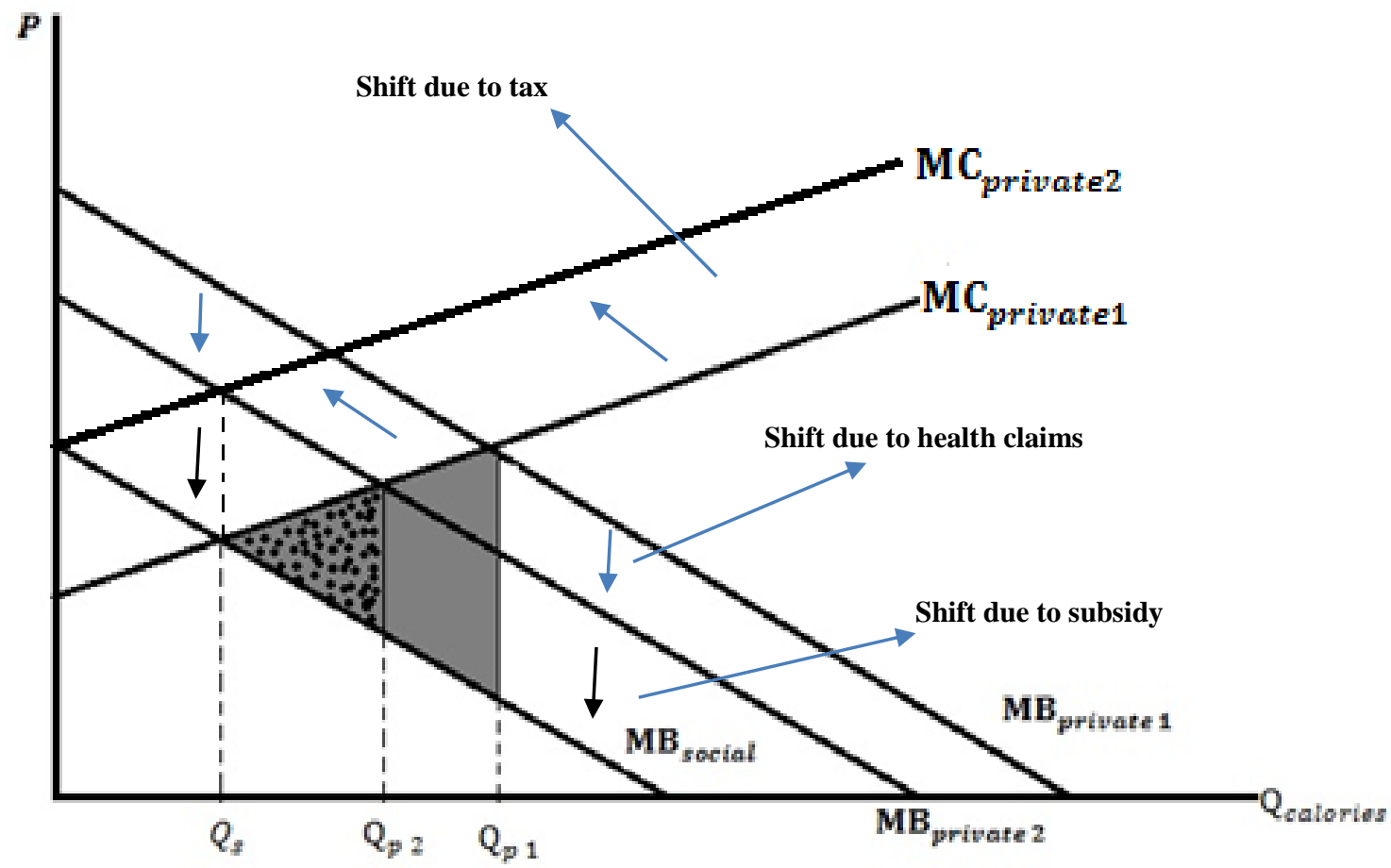

Source: authors' calculations.

An alternative to a subsidy on low calorie foods would be a governmentimposed Pigovian tax on high calorie diets. Okrent and Alston (2012) found taxing of calories to be a significant way to reduce obesity prevalence and increase net social benefits. An example of such taxes is a "fat tax", which is intended to discourage the consumption of unhealthy foods that likely lead to obesity and its

\footnotetext{
${ }^{19}$ All other things being equal, the introduction of subsidies on foods that are low in calories but are close substitutes to those that are high in calories might entice consumers to substitute the low calorie diets for the high calorie ones.
} 
related health problems (e.g., Cash et al. 2005, Leicester and Windmeijer 2004, Mytton et al. 2007). Similar to such a policy is the tax on tobacco products, which has led to a significant reduction of tobacco consumption and improved health in the UK (e.g., Mytton et al. 2007). Other countries with such taxes include Hungary (where there is a public health tax on sugary drinks and unhealthy foods) and Mexico - where there is $10 \%$ tax on sugary drinks and $8 \%$ tax on unhealthy snacks (FPI Australian Governments 2017). Figure 2 shows the impact of a fat tax on the price and quantity of unhealthy foods consumed, such as high calorie diets. Imposition of the appropriate amount of tax on high calorie diets (or foods high in fats) increases the price of high calorie foods, causing the marginal cost private curve to shift upwards to the left from $\mathrm{MC}_{\text {private } 1}$ to $\mathrm{MC}_{\text {private } 2}$, as depicted in Figure 2. Therefore, the quantity demanded of high calorie foods will be reduced from $Q_{p 2}$ to $Q_{s}$. At $Q_{s}$, and there is no deadweight loss to society ${ }^{20}$.

Proper implementation of fat taxes on high calorie foods could discourage the consumption of unhealthy foods. Giesen et al. (2012) found taxes on high calorie diets to be more effective than subsidies on low calorie diets. However, numerous studies have shown that if such taxes are not properly implemented, they could cause more harm than the intended good, as in the case of Denmark (e.g., Chouinard et al. 2007, Taylor 2013). Denmark abolished the "fat tax" just a year after its implementation. Among the challenges of using taxes as an intervention measure to address obesity problems are the substitution effect and the elasticity of demand for the food product on which the tax is imposed. Imposing taxes on certain food products might lead to the substitution of unhealthier foods which could further worsen the obesity problem. Moreover, depending on how responsive consumers are to changes in the price of such products, an intervention policy based on tax might or might not be successful. For example, a tax on food products with fairly elastic demand might be successful in reducing the quantity demanded of such products. However, irrespective of how high a tax on an unhealthy food may be, if the product is highly inelastic, the impact of the tax might be minimal or totally ineffective. The challenge for policy makers is to accurately measure the responsiveness of the demand for the unhealthy diets. Another challenge associated with the implementation of taxes on unhealthy diets is how to accurately measure the "healthiness/unhealthiness" of a food product. Thus, a tax intervention policy might be successful or not depending on factors like the nature of the product (i.e., necessity, luxury, availability/proximity of close substitutes, time period, etc.).

\section{Conclusion}

Increasing mortality and morbidity rates, in addition to the continuous rise in health care costs, have become significant health and policy concerns in Canada and the world at large. The total economic impact of obesity is about $\$ 2$ trillion a

\footnotetext{
${ }^{20}$ In practice, though the introduction of tax might cause a reduction in caloric intake towards the socially optimal level, such reduction might not necessarily coincide with the socially optimal level.
} 
year or $2.8 \%$ of world GDP, while nearly $30 \%$ of the global population is overweight or obese. Obesity, which is strongly associated with several diseases, is increasingly becoming a pressing health care concern. We assessed the potential economic benefits of the reduction of obesity incidence, which, potentially, could be achieved by the successful implementation and promotion of the health claim on low calorie diets and obesity in Canada using nationwide Body Mass Index data. The study followed an integrated approach that enabled us to systematically, consistently, and broadly analyse the issue of obesity and, in turn, to make policy recommendations that could significantly contribute to the reduction of the obesity epidemic.

Findings from the simulation of actual data on measured heights and weights of Canadians suggested that a 5 to 10 percent weight loss arising from a reduction in caloric intake due to potential implementation and promotion of healthinformation/health-claim on "low calorie diets and obesity" results in nontrivial health-related cost savings. The mean health-related average cost savings was projected to be $\$ 1.93$ billion (base case). Based on the findings, several policy recommendations were discussed. It was shown that even a modest weight loss resulting from lower caloric intake (i.e., 5 percent), could significantly reduce the incidence of obesity in Canada and thereby lead to a reduction in the health care expenditure on the disease. This study recommends the following main intervention measures to tackle the obesity problem: the implementation and promotion of a health claim on low calorie diets and obesity; nationwide introduction of obesity education campaigns; the introduction of subsidies on healthy foods with low calorie contents; and the introduction of taxes on unhealthy foods with overblown calorie contents.

Obesity has become a crisis that is not just a pressing health concern but also a threat to the global economy. In general, in order to reverse the health burden of obesity, a systemic and sustained portfolio of initiatives that could be delivered at scale is needed - no single intervention is likely to have a significant overall impact. Education and personal responsibility are critical elements of any program aiming to reduce obesity incidence and related health care costs; however they are not sufficient on their own. Hence, a combination of initiatives and co-operation of all sectors involved (e.g., media organizations, educators, healthcare providers, consumers, public sector), as well as government interventions, will be required to change public health outcomes and to reduce health costs.

In closing, this study provides vital findings and recommendations regarding the pressing health and economic concern of obesity. It generated reasonable estimates of the potential benefits from the reduction of obesity incidents, potentially from health claims, as well as followed an integrated approach of examining the obesity epidemic while emphasising the regulatory policies and initiatives to address the issue. However, we acknowledge some unavoidable limitations and fruitful areas for further research regarding the available market data on products carrying health claims and the extent to which a health claim has actually stimulated increased consumption of low-calorie diets. As more information regarding the efficacy of specific health claims and updated nationwide BMI data become available, it will allow a further refinement of the estimates 
presented in this paper. However, it is expected that the core findings will remain the same; as well as the direction of the effect with even larger magnitude of the health cost savings.

\section{References}

Alston JM, Okrent AM, and Parks JC (2012) US food policy and obesity. INTECH Open Access Publisher.

Alston JM, Okrent AM, Parks J (2013) Effects of US public agricultural R\&D on US obesity and its social costs. In 2013 Conference $\left(57^{\text {th }}\right)$, February 5-8, 2013, Sydney, Australia. Australian Agricultural and Resource Economics Society.

Alter DA, Wijeysundera HC, Franklin B, Austin PC, Chong A, Oh PI et al. (2012) Obesity, lifestyle risk-factors, and health service outcomes among healthy middleaged adults in Canada. BMC Health Services Research 12(1): 238.

Ananthapavan J, Sacks G, Moodie M, Carter R (2014) Economics of obesity—Learning from the past to contribute to a better future. International Journal of Environmental Research and Public Health 1(4): 4007-4025.

Anis AH, Zhang W, Bansback N, Guh DP, Amarsi Z, Birmingham CL (2010) Obesity and overweight in Canada: an updated cost of illness study. Obesity Reviews 11(1): $31-40$.

Aschemann-Witzel J, Hamm U (2010) Do consumers prefer foods with nutrition and health claims? Results of a purchase simulation. Journal of Marketing Communications 16(1-2): 47-58.

Barreiro-Hurlé J, Colombo S, Cantos-Villar E (2008) Is there a market for functional wines? Consumer preferences and willingness to pay for resveratrol-enriched red wine. Food Quality and Preference 19(4): 360-371.

Barreiro-Hurlé J, Gracia A, De-Magistris T (2010) Does nutrition information on food products lead to healthier food choices? Food Policy 35(3): 221-229.

Bélanger-Ducharme F, Tremblay A (2005) Prevalence of obesity in Canada. Obesity Reviews 6(3): 183-186.

Birmingham CL, Muller JL, Palepu A, Spinelli JJ, Anis AH (1999) The cost of obesity in Canada. Canadian Medical Association Journal 160(4): 483-488.

Brown DJ, Schrader LF (1990) Cholesterol information and shell egg consumption. American Journal of Agricultural Economics 72(3): 548-555.

Canadian Institute for Health Information - CIHI (2013) National health expenditure trends, 1975 to 2013. Canadian Institute for Health Information. Retrieved from: https://secure.cihi.ca/free_products/NHEXTrendsReport_EN.pdf. [Accessed 26 October 2020]

Canadian Institute for Health Information - CIHI (2014) National health expenditure trends, 1975 to 2014. Retrieved from: https://bit.ly/3pcE3yG. [Accessed 26 October 2020]

Canadian Institute for Health Information - CIHI (2017) Health spending. Retrieved from: www.cihi.calen/health-spending. [Accessed 26 October 2020]

Cash SB, Sunding DL, Zilberman D (2005) Fat taxes and thin subsidies: prices, diet, and health outcomes. Acta Agriculturae Scand Section C 2(3-4): 167-174.

Cawley J (2004) An economic framework for understanding physical activity and eating behaviors. American Journal of Preventive Medicine 27(3): 117-125.

Cawley J (2010) The economics of childhood obesity. Health Affairs 29(3): 364-371. 
Chang VW, Lauderdale DS (2005) Income disparities in body mass index and obesity in the United States, 1971-2002. Archives of Internal Medicine 165(18): 2122-2128.

Chouinard H, Davis D, LaFrance J, Perloff J (2007) Fat taxes: big money for small change. Forum for Health Economics \& Policy: Timely and Evolving Forums on Important Health Care Issues [E] 10(2): 1-28.

Civitarese AE, Carling S, Heilbronn LK, Hulver MH, Ukropcova B, Deutsch WA et al. (2007) Calorie restriction increases muscle mitochondrial biogenesis in healthy humans. PLoS Medicine 4(3): e76.

Colman RJ, Anderson RM, Johnson SC, Kastman EK, Kosmatka KJ, Beasley TM et al. (2009) Caloric restriction delays disease onset and mortality in rhesus monkeys. Science 325(5937): 201-204.

Edwards M (2007) An econometric analysis of overweight and obesity in Canada: evidence from cycle 2.2 of the Canadian community health survey. Canada: University of New Brunswick.

Efrat MW, Efrat R (2012) Tax policy and the obesity epidemic. Journal of Law and Health 25(2): 233.

Elston JA, Stanton KR, Levy DT, Acs ZJ (2010) Tax solutions to the external costs of obesity. Obesity, Business and Public Policy, Chapter 10, 171-188. Edward Elgar Publishing.

Epstein LH, Handley EA, Dearing KK, Cho DD, Roemmich JN, Paluch RA et al. (2006) Purchases of food in youth: influence of price and income. Psychological Science 17(1): 82-89.

Fontana L, Meyer TE, Klein S, Holloszy JO (2004) Long-term calorie restriction is highly effective in reducing the risk for atherosclerosis in humans. Proceedings of the National Academy of Sciences of the United States of America 101(17): 6659-6663.

Fontana L, Villareal DT, Weiss EP, Racette SB, Steger-May K, Klein S et al. (2007) Calorie restriction or exercise: effects on coronary heart disease risk factors. A randomized, controlled trial. American Journal of Physiology-Endocrinology and Metabolism 293(1): E197-E202.

FPI Australian Governments (2017) Policies for tackling obesity and creating healthier food environments: scorecard and priority recommendations for Australian govern ments. FPI Australian Governments. Retrieved from: https://bit.ly/314Fn4b. [Accessed 25 October 2020]

Franssila-Kallunki A, Rissanen A, Ekstrand A, Ollus A, Groop L (1992) Weight loss by very-low-calorie diets: effects on substrate oxidation, energy expenditure, and insulin sensitivity in obese subjects. The American Journal of Clinical Nutrition 56(1): 247S-248S.

Freebairn J (2010) Taxation and obesity? Australian Economic Review 43(1): 54-62.

French SA (2003) Pricing effects on food choices. The Journal of Nutrition 133(3): 841S$843 \mathrm{~S}$.

Giesen JC, Havermans RC, Nederkoorn C, Jansen A (2012) Impulsivity in the supermarket. Responses to calorie taxes and subsidies in healthy weight undergraduates. Appetite 58(1): 6-10.

Godin K, Leatherdale ST, Elton-Marshall T (2015) A systematic review of the effectiveness of school-based obesity prevention programmes for First Nations, Inuit and Métis youth in Canada. Clinical obesity 5(3):103-15.

Goldman D, Lakdawalla D, Zheng Y (2011) Food prices and the dynamics of body weight. USA: University of Chicago Press.

Gray R, Malla S, Stephen A (1998) Canadian dietary fat substitutions, 1955-93, and coronary heart disease costs. Canadian Journal of Agricultural Economics/ Revue Canadienne d'Agroeconomie 46(2): 233-246. 
Guarente L, Picard F (2005) Calorie restriction-The SIR2 connection. Cell 120(4): 473482.

Gyles CL, Carlberg JG, Gustafson J, Davlut DA, Jones PJH (2010) Economic valuation of the potential health benefits from foods enriched with plant sterols in Canada. Food and Nutrition Research 54(1): 5113.

Hagan RD, Upton SJ, Wong L, Whittam J (1986) The effects of aerobic conditioning and/or caloric restriction in overweight men and women. Medicine and Science in Sports and Exercise 18(1): 87-94.

Health Canada (1998) Nutraceuticals/Functional foods and health claims on foods. Policy Paper. Retrieved from: https://bit.ly/3exrg4M. [Accessed 26 October 2020]

Health Canada (2009) Guidance document for preparing a submission for food health claims. Bureau of Nutritional Sciences Food Directorate, Health Products and Food Branch Health Canada. Retrieved from: https://bit.ly/2IeclQM. [Accessed 26 October 2020]

Health Canada (2012) Health claims. Retrieved from: http://www.hc-sc.gc.ca/fn-an/labeletiquet/claims-reclam/index-eng.php. [Accessed 26 October 2020]

Health Canada (2020) Novel foods. Retrieved from: http://www.hc-sc.gc.ca/fn-an/gmfagm/fs-if/novel-foods-aliments-nouveaux-eng.php. [Accessed 26 October 2020]

Heilbronn LK, de Jonge L, Frisard MI, DeLany JP, Larson-Meyer DE, Rood J et al. (2006) Effect of 6-month calorie restriction on biomarkers of longevity, metabolic adaptation, and oxidative stress in overweight individuals: a randomized controlled trial. Jama 295(13): 1539-1548.

Hobbs JE, Malla S, Sogah EK, Yeung MT (2014) regulating health foods: policy challenges and consumer conundrums. Cheltenham, UK: Edward Elgar Publishing Ltd.

Initiative NOE (1998) Clinical guidelines on the identification, evaluation, and treatment of overweight and obesity in adults. National Heart, Lung, and Blood Institute.

Ippolito PM, Mathios AD (1991) Health claims in food marketing: evidence on knowledge and behavior in the cereal market. Journal of Public Policy \& Marketing 10(1): 1532.

Katzmarzyk PT, Craig CL, Bouchard C (2001) Original article underweight, overweight and obesity: relationships with mortality in the 13-year follow-up of the Canada Fitness Survey. Journal of Clinical Epidemiology 54(9): 916-920.

Kelly T, Yang W, Chen C-S, Reynolds K, He J (2008) Global burden of obesity in 2005 and projections to 2030. International Journal of Obesity 32(9): 1431.

Kok P, Roelfsema F, Langendonk JG, Frölich M, Burggraaf J, Meinders AE et al. (2005) High circulating thyrotropin levels in obese women are reduced after body weight loss induced by caloric restriction. The Journal of Clinical Endocrinology \& Metabolism 90(8): 4659-4663.

Kozup JC, Creyer EH, Burton S (2003) Making healthful food choices: the influence of health claims and nutrition information on consumers' evaluations of packaged food products and restaurant menu items. Journal of Marketing 67(2): 19-34.

Lalor F, Madden C, McKenzie K, Wall PG (2011) Health claims on foodstuffs: a focus group study of consumer attitudes. Journal of Functional Foods 3(1): 56-59.

Larson-Meyer DE, Heilbronn LK, Redman LM, Newcomer BR, Frisard MI, Anton S et al. (2006) Effect of calorie restriction with or without exercise on insulin sensitivity, $\beta$-cell function, fat cell size, and ectopic lipid in overweight subjects. Diabetes Care 29(6): 1337-1344.

Larue B, West GE, Gendron C, Lambert R (2004) Consumer response to functional foods produced by conventional, organic, or genetic manipulation. Agribusiness 20(2): $155-166$. 
Le Petit C, Berthelot J-M (2005) Obesity: a growing issue. Statistics Canada. Retrieved from: http://www.publications.gc.ca/Collection/Statcan/82-618-M/82-618-MIE2005 003.pdf. [Accessed 26 October 2020]

Leicester A, Windmeijer F (2004) The "fat tax": economic incentives to reduce obesity. Retrieved from: http://discovery.ucl.ac.uk/14931/1/14931.pdf. [Accessed 26 October 2020]

Levy AS, Stokes RC (1987) Effects of a health promotion advertising campaign on sales of ready-to-eat cereals. Public Health Reports 102(4): 398.

Loewenstein G, Brennan T, Volpp KG (2007) Asymmetric paternalism to improve health behaviors. Jama 298(20): 2415-2417.

Ludwig DS, Pollack HA (2009) Obesity and the economy: from crisis to opportunity. Jama 301(5): 533-535.

Luo W, Morrison H, De Groh M, Waters C, Des Meules M, Jones-McLean E et al. (2007) The burden of adult obesity in Canada. Chronic Diseases in Canada 27(4): 135.

Malla S, Hobbs JE, Perger O (2007) Valuing the health benefits of a novel functional food. Canadian Journal of Agricultural Economics 55(1): 115-136.

Malla S, Hobbs J, Sogah EK (2013) Functional foods and natural health products regulations in Canada and around the world: nutrition labels and health claims. Publication 36. Saskatoon, SK: Canadian Agricultural Innovation and Regulation Network (CAIRN).

Malla S, Hobbs JE, Sogah EK (2016) Estimating the potential benefits of new health claims in Canada: the case of soluble fiber and soy protein. Canadian Journal of Agricultural Economics/Revue Canadienne d' Agroeconomie 64(1): 173-1197.

Marette S, Roosen J, Blancheman S, Feinblatt-Meleze E (2010) Functional food, uncertainty and consumers' choices: a lab experiment with enriched yoghurts for lowering cholesterol. Food Policy 35(5): 419-428.

Maynard LJ, Franklin ST (2003) Functional foods as a value-added strategy: the commercial potential of "cancer-fighting" dairy products. Review of Agricultural Economics 25(2): 316-331.

Miller WC, Koceja D, Hamilton E (1997) A meta-analysis of the past 25 years of weight loss research using diet, exercise or diet plus exercise intervention. International Journal of Obesity 21(10): 941-947.

Milligan MA, Bohara AK, Pagán JA (2010) Assessing willingness to pay for cancer prevention. International Journal of Health Care Finance and Economics 10(4): 301-314.

Moodie R, Swinburn B, Richardson J, Somaini B (2006) Childhood obesity-A sign of commercial success, but a market failure. International Journal of Pediatric Obesity 1(3): 133-138.

Moon W, Balasubramanian SK, Rimal A (2011) Health claims and consumers' behavioral intentions: the case of soy-based food. Food Policy 36(4): 480-489.

Moyer VA (2012) Screening for and management of obesity in adults: US preventive services task force recommendation statement. Annals of Internal Medicine 157(5): 373-378.

Muller L, Lacroix A, Lusk JL, Ruffieux B (2017) Distributional impacts of fat taxes and thin subsidies. The Economic Journal 127(604): 2066-2092.

Mytton O, Gray A, Rayner M, Rutter H (2007) Could targeted food taxes improve health? Journal of Epidemiology and Community Health 61(8): 689-694.

$\mathrm{Ng} \mathrm{M}$, Fleming T, Robinson M, Thomson B, Graetz N, Margono C et al. (2014) Global, regional, and national prevalence of overweight and obesity in children and adults during 1980-2013: a systematic analysis for the global burden of disease study 2013. The Lancet 384(9945): 766-781. 
Okrent AM, Alston JM (2012) The effects of farm commodity and retail food policies on obesity and economic welfare in the United States. American Journal of Agricultural Economics 94(3): 611-646.

Pollan M (2007) You are what you grow. The New York Times Magazine.

Public Health Agency of Canada (2009) Obesity in Canada - Snapshot. Retrieved from: https://www.canada.ca/en/public-health/services/reports-publications/obesity-canadasnapshot.html. [Accessed 26 October 2020]

Public Health Agency of Canada (2011) Obesity in Canada. A Joint Report from the Public Health Agency of Canada and the Canadian Institute for Health Information. Retrieved from: http://www.phac-aspc.gc.ca/hp-ps/hl-mvs/oic-oac/index-eng.php. [Accessed 26 October 2020]

Public Health Agency of Canada (2014) Economic burden of illness in Canada 20052008. Retrieved from: http://www.phac-aspc.gc.ca/publicat/ebic-femc/2005-2008/in dex-eng.php. [Accessed 26 October 2020]

Puddey I, Parker M, Beilin L, Vandongen R, Masarei J (1992) Effects of alcohol and caloric restrictions on blood pressure and serum lipids in overweight men. Hypertension 20(4): 533-541.

Racette SB, Weiss EP, Villareal DT, Arif H, Steger-May K, Schechtman KB et al. (2006) One year of caloric restriction in humans: feasibility and effects on body composition and abdominal adipose tissue. The Journals of Gerontology Series A: Biological Sciences and Medical Sciences 61(9): 943-950.

Redman LM, Heilbronn LK, Martin CK, Alfonso A, Smith SR, Ravussin E (2007) Effect of calorie restriction with or without exercise on body composition and fat distribution. The Journal of Clinical Endocrinology \& Metabolism 92(3): 865-872.

Redman LM, Heilbronn LK, Martin CK, De Jonge L, Williamson DA, Delany JP et al. (2009) Metabolic and behavioral compensations in response to caloric restriction: implications for the maintenance of weight loss. PloS One 4(2): e4377.

Rickard BJ, Okrent AM, Alston JM (2013) How have agricultural policies influenced caloric consumption in the United States? Health Economics 22(3): 316-339.

Roberts RR, Frutos PW, Ciavarella GG, Gussow LM, Mensah EK, Kampe LM et al. (1999) Distribution of variable vs fixed costs of hospital care. Jama 281(7): 644-649.

Roberts KC, Shields M, de Groh M, Aziz A, Gilbert J-A (2012) Overweight and obesity in children and adolescents: results from the 2009 to 2011. Canadian Health Measures Survey. Health Reports 23(3): 37-41.

Ross R., Dagnone D, Jones PJ, Smith H, Paddags A, Hudson R et al. (2000) Reduction in obesity and related comorbid conditions after diet-induced weight loss or exerciseinduced weight loss in men: a randomized, controlled trial. Annals of Internal Medicine 133(2): 92-103.

Rothman RL, Housam R, Weiss H, Davis D, Gregory R, Gebretsadik T et al. (2006) Patient understanding of food labels: the role of literacy and numeracy. American Journal of Preventive Medicine 31(5): 391-398.

Statistics Canada (2019) Consumer price index: health and personal care, by province (Canada). CANSIM table. Retrieved from: http://www.statcan.gc.ca/tables-tableaux/ sum-som/101/c st01/econ161a-eng.htm. [Accessed 26 October 2020]

Strand J (2005) Conceptualizing the-Fat Taxll: The Role of Food Taxes in Developed Countries. SSRN Electronic Journal 78(5): 1221-1240.

Swinburn BA, Sacks G, Hall KD, McPherson K, Finegood DT, Moodie ML et al. (2011) The global obesity pandemic: shaped by global drivers and local environments. The Lancet 378(9793): 804-814. 
Tan AK, Dunn RA, Samad MIA, Feisul MI (2011) Sociodemographic and health-lifestyle determinants of obesity risks in Malaysia. Asia-Pacific Journal of Public Health 23(2): 192-202.

Taylor PS (2013) Tax on the menu: why taxing food and drink won't make Canadians thinner, but will make their governments much, much fatter. Canadian Taxpayers Federation Report. Retrieved from: https://bit.ly/3k2icpG. [Accessed 26 October 2020]

Teratanavat R, Hooker NH (2006) Consumer valuations and preference heterogeneity for a novel functional food. Journal of Food Science 71(7): S533-S541.

Tiffin R, Arnoult M (2011) The public health impacts of a fat tax. European Journal of Clinical Nutrition 65(4): 427-433.

Tjepkema M (2006) Adult obesity. Health Reports 17(3): 9-25.

Torrance G, Hooper M, Reeder B (2002) Trends in overweight and obesity among adults in Canada (1970-1992): evidence from national surveys using measured height and weight. International Journal of Obesity and Related Metabolic Disorders: Journal of the International Association for the Study of Obesity 26(6): 797-804.

Tsai AG, Wadden TA (2006) The evolution of very-low-calorie diets: an update and metaanalysis. Obesity 14(8): 1283-1293.

Villareal DT, Fontana L, Weiss EP, Racette SB, Steger-May K, Schechtman KB et al. (2006) Bone mineral density response to caloric restriction-induced weight loss or exercise-induced weight loss: a randomized controlled trial. Archives of Internal Medicine 166(22): 2502-2510.

Wadden TA, Foster GD, Letizia KA (1994) One-year behavioral treatment of obesity: comparison of moderate and severe caloric restriction and the effects of weight maintenance therapy. Journal of Consulting and Clinical Psychology 62(1): 165171.

Wadden TA, Considine RV, Foster GD, Anderson DA, Sarwer DB, Caro JS (1998) Shortand long-term changes in serum leptin in dieting obese women: effects of caloric restriction and weight loss 1. The Journal of Clinical Endocrinology \& Metabolism 83(1): 214-218.

Wansink B, Cheney MM (2005) Leveraging FDA health claims. Journal of Consumer Affairs 39(2): 386-398.

Weiss EP, Racette SB, Villareal DT, Fontana L, Steger-May K, Schechtman KB et al. (2007) Lower extremity muscle size and strength and aerobic capacity decrease with caloric restriction but not with exercise-induced weight loss. Journal of Applied Physiology 102(2): 634-640.

West GE, Gendron C, Larue B, Rémy L (2002) Consumers' valuation of functional properties of foods: results from a Canada-wide survey. Canadian Journal of Agricultural Economics 50(4): 541-558.

Williams P (2005) Consumer understanding and use of health claims for foods. Nutrition Reviews 63(7): 256-264.

Wing RR, Blair E, Marcus M, Epstein LH, Harvey J (1994) Year-long weight loss treatment for obese patients with type II diabetes: does including an intermittent verylow-calorie diet improve outcome? The American Journal of Medicine 97(4): 354362.

Word Health Organization - WHO (2003) Diet, nutrition and the prevention of chronic diseases. WHO Technical Report Series, 916. Report of a Joint WHO/FAO Expert Consultation. Geneva: WHO.

Word Health Organization - WHO (2013) Margaret Chan, WHO Director-General addresses health promotion conference. Opening Address at the $8^{\text {th }}$ Global Conference on Health Promotion, Helsinki, Finland, 10 June 2013. Retrieved from: 
http://www.who.int/dg/speeches/2013/health_promotion_20130610/en/. [Accessed 26 October 2020]

\section{Appendix 1}

Step 1

Table A.1. Results of the Meta-Analysis to Determine the Average Weight Loss Resulting from Calorie Restriction (CR)

\begin{tabular}{|c|c|c|c|c|c|c|c|}
\hline \multirow[b]{2}{*}{ Authors(S) } & \multirow[b]{2}{*}{ Year } & \multirow{2}{*}{$\begin{array}{c}\text { CR } \\
\text { intervention } \\
\text { period } \\
\text { (months) }\end{array}$} & \multirow[b]{2}{*}{ Type of CR } & \multirow[b]{2}{*}{$\begin{array}{c}\text { Reduction } \\
\text { in weight } \\
(\%)\end{array}$} & \multirow[b]{2}{*}{$\begin{array}{c}\text { Deviation } \\
\pm(\%)\end{array}$} & \multicolumn{2}{|c|}{ Range } \\
\hline & & & & & & $\begin{array}{c}\text { LOW } \\
(\%)\end{array}$ & $\begin{array}{c}\text { HIGH } \\
(\%)\end{array}$ \\
\hline Hagan et al. & 1986 & 3 & LCD & $8.5^{* * * *}$ & 0.7 & 7.8 & 9.2 \\
\hline Franssila-Kallunki et al. & 1992 & 2 & VLCD & 10.5 & 0.1 & 10.4 & 10.6 \\
\hline Puddey et al. & 1992 & 4.5 & LCD & $10.8^{*}$ & 1 & 9.8 & 11.8 \\
\hline Wing et al. & 1994 & 12 & LCD & 9.7 & 0 & 9.7 & 9.7 \\
\hline Miller et al. & 1997 & 3.8 & LCD & 11.1 & 0.4 & 10.7 & 11.5 \\
\hline Wadden et al. & 1998 & 5 & LCD & $13.2^{*}$ & 5.7 & 7.5 & 18.9 \\
\hline Ross et al. & 2000 & 3 & LCD & 8 & 0 & 8 & 8 \\
\hline Kok et al. & 2005 & 4 & VLCD & $14.6^{*}$ & 0.4 & 14.2 & 15 \\
\hline Villareal et al. & 2006 & 12 & LCD & 10.7 & 6.3 & 4.4 & 17 \\
\hline Heilbronn et al. & 2006 & 6 & LCD & 10.4 & 0.9 & 9.5 & 11.3 \\
\hline Racette et al. & 2006 & 12 & LCD & 10.7 & 0 & 10.7 & 10.7 \\
\hline Larson-Meyer et al. & 2006 & 6 & LCD & 10.1 & 1 & 9.1 & 11.1 \\
\hline Tsai et al. & 2006 & 1 & LCD & 9.7 & 2.4 & 7.3 & 12.1 \\
\hline Redman et al. & 2007 & 6 & LCD & 10.4 & 0.9 & 9.5 & 11.3 \\
\hline Weiss et al. & 2007 & 9 & LCD & 10.7 & 1.4 & 9.3 & 12.1 \\
\hline Fontana et al. & 2007 & 12 & LCD & $10.9 * *$ & 2.1 & 8.8 & 13 \\
\hline Redman et al. & 2009 & 6 & LCD & 10.4 & 0.9 & 9.5 & 11.3 \\
\hline
\end{tabular}

Average Weight Loss $=10.61 \% \pm 1.42 \%$

NB: *calculated by authors. **calculated by authors from BMI changes. ***calculated by finding the average weight loss between men and women.

Source: authors' calculation.

\section{Appendix 2}

\section{Step 3: Second Scenario, "Base"}

Cost of obesity can be grouped into direct and indirect. As less incidence of obesity will result in fewer cases of obesity related mortalities and morbidities, it is assumed that a reduction in obesity prevalence will result in a proportionate reduction in the indirect cost of obesity.

"Hospital care" expenditure represents the highest component of the direct cost of obesity. Generally, irrespective of the level of disease incidence, there will still be some cost incurred in the running of the hospital (Gyles et al. 2010). It has been estimated that more than three fourths of hospital expenditure is fixed. Approximately 84 percent of hospital expenditure has been estimated to be fixed with the remaining 16 percent being variable (Gyles et al. 2010, Roberts et al. 1999). Since the fixed cost component of the hospital expenditure may not immediately respond to the reduction in the prevalence of obesity in the short run, 
it is assumed that only the variable component of the cost will change proportionally to the change in obesity prevalence. That is, a 1 percent reduction in obesity prevalence will lead to a 0.16 percent reduction in hospital cost.

"Drug" cost of obesity is the second highest component of obesity cost. Taking total drug cost into consideration, approximately 84.9 percent is prescribed and the remaining 15.1 percent is non-prescribed (CIHI 2014). Since lower cases of obesity will result in lower prescription of obesity drugs, a linear relationship (i.e., 1:1) is therefore assumed between changes in obesity prevalence and changes in the prescription of drugs. Non-prescription drugs, which are mainly over-thecounter (OTC) drugs and personal health supplies (PHS), were not included in the analysis because it may not immediately respond to a reduction in obesity prevalence. Therefore, the relationship between obesity prevalence reduction and reduction in drug cost becomes 1:0.85.

'Physician' services may not be required if one is not sick or ill. As such, it is expected that fewer cases of obesity and its related comorbidities will result in fewer physician visits. Fewer physician visits will also imply a reduction in physician service expenditure. It is, therefore, assumed that a reduction in the prevalence of obesity will lead to a proportionate reduction in the cost incurred on the services of physicians (i.e., 1:1 relationship).

"All other health cost" represents the expenditure on services of "other health professionals", "other health care", and "research". The expenditure incurred for the services of "other health professionals" can be grouped into three main categories: namely "dental care cost", "vision care", and "others". The "others" category comprises expenditure on massage therapists, chiropractors, physiotherapists, podiatrists, and psychologists (CIHI 2014). It is expected that a reduction in the prevalence of obesity will not necessarily result in a reduction in the expenditure incurred on dental care and vision care. As such, they are excluded from the analysis. The proportion of expenditure on the services of other health professionals that go to dental care and vision care are 61.1 percent and 19.2 percent respectively. Therefore, the relationship between the reduction in obesity prevalence and reduction in expenditure on other health professionals becomes 1:0.20. Furthermore, expenditure on "other health care" mostly includes expenses on home care and medical transportation (CIHI 2014). The majority of this expenditure is considered fixed and, as such, a reduction in the prevalence of obesity may not affect it in the short term. Finally, expenditure on health "research" is also considered largely fixed and was excluded from the analysis.

The weighted average of all direct and indirect costs is equal to 0.83 (weighted by the expenditure incurred on each component of the total health cost). 
Table A.2. Percentage Reduction in Health-Related Cost Components Resulting from a $1 \%$ Reduction in Disease Incidence

\begin{tabular}{|l|c|c|}
\hline Obesity cost components & Percentage reduction in cost & $\begin{array}{c}\text { Cost } \\
\text { (million \$) }\end{array}$ \\
\hline Hospital care & 0.16 & 9757.9 \\
\hline Physician & 1.00 & 2480.0 \\
\hline Drug & 0.85 & 4960.5 \\
\hline All other health cost* & 0.20 & 4462.4 \\
\hline Indirect cost & 1.00 & 52600.0 \\
\hline
\end{tabular}

Weighted average $=0.83$

*"All other health cost" represents the expenditure on services of other health professionals, other health care, and research. The cost of the various subcomponents of the "all other health cost" category are: other health professionals- $\$ 396.9$, other health care- $\$ 3729.7$ and research- $\$ 335.8$ (all amounts are in millions of dollars).

Source: Anis et al. (2010) and authors' calculation. 